\title{
USE OF GEOGRAPHICAL INFORMATION SYSTEM FOR THE EVALUATION OF SOLID WASTE MANAGEMENT PRACTICE IN KHULNA CITY
}

\author{
Smita Golder and Muhammed Alamgir * \\ Department of Civil Engineering, Khulna University of Engineering and Technology, Khulna-9203, Bangladesh
}

Article Info:
Received:
5 February 2018
Revised:
5 September 2018
Accepted:
17 October 2018
Available online:
23 November 2018
Keywords:
Geographic information system
Municipal solid waste
Waste generation
Waste container
Waste collection

\section{INTRODUCTION}

Urban solid waste management is considered as one of the most instantaneous and momentous environmental problems, faced by developing Asian Countries. Municipal Solid Waste Management (MSWM) is one kind of responsibility combining various activities such as collection, transportation, disposal, processing and treatment of solid waste. As the world is approaching to the urban future and economic development, managing solid waste crisis is undoubtedly one of the key challenges of the $21^{\text {th }}$ century. The increasing volume of waste along with the rapid economic headway and globalization is creating a serious difficulty to ecosystems and human health. The problem of municipal solid waste management has acquired an alarming dimension in the developing countries during the last few decades. Compared to high income countries, the urban residents of developing countries produce less per capita solid waste, but the capacity of developing countries to collect, process disposal or reuse it in a cost effective way is limitted (Visvanathan and Trankler, 2004).

High-tech evolution, the rapid economic headway, globalization, overpopulation, affluence, lack of proper garbage collection have accelerated the dynamics of the urbanization process in advancing countries. Waste management questions are approaching to the forefront of the global habitat schedule at an enlarging amount. Municipal solid waste consists of domestic waste generated by urban residents (households) with addition of commercial wastes but typically excludes industrial hazardous waste and domestic sewage sludge (James, 1997). The waste generated by households in urban areas constitutes a significant component of the municipal solid waste generated and therefore it has a direct bearing on the design of municipal waste management systems (Benitez, 2008). Compared to high income countries, the urban residents of developing countries produce less per-capita solid waste, but the capacity of the developing countries to collect, process, dispose or reuse the solid waste in a cost-effective way is limited (Visvanathan and Trankler, 2004).

Khulna, the third largest metropolitan city of Bangladesh, generates a massive quantity of waste every day from different sources. Khulna city normally generates 500 tonnes per day of solid waste every day. Of the total, only 270 TO 300 tonnes are collected and dumped into the open dumping ground at Rajbando landfills of Batiaghata upazila. The rest that lies uncollected on Khulna city streets every day due to poor monitoring and logistic supports and negligence of the field-level corporation workers and officials, exposes the residents to greater health risks and environmental hazards. The remaining uncollected wastes are dumped into drains, open spaces, road-sides and water-bodies, not only blocking the city's drainage links but also creating an unhealthy and stinking environment. Due to dumping into open areas, airborne and waterborne
* Corresponding author

Muhammed Alamgir

email: alamgir63dr@yahoo.com 
diseases such as like diarrhea, dysentery, jaundice and skin diseases can be spread out and the fitness condition of people may be at risk.

Recently, there has been an increase in research that uses Geographic Information System (GIS) application as a tool for MSW management estimation and planning. MSW management practices require collection of decisive information which is for taking corrective measures as well as for proper planning to ensure sustainability (Ramachandra and Saira, 2003). GIS is a computer system capable of holding and using data describing places on the earth's surface. GIS is a good decision support tool for SWM planning. To analysis the present SWM practice and to identify the served and un-served area from the coverage GIS map in KCC are the specific objectives of the study.

\section{LITERATURE REVIEW}

Literature on solid waste management is extensive in scope and comparison for both developed countries as well as for developing countries. To solve the inherent problems regarding solid waste management using GIS, particularly for developing countries, several specific researches have been done.

According to (Kathiravale, Muhd Yunus, 2008), it is reported that developed countries generally generate more waste than developing countries. The generation of waste varies considerably between countries based on the culture, public awareness and management (Hazra and Goel, 2009; Wagner and Arnold, 2008). According to Sujauddin et al. (2008) the generation of waste is influenced by family size, their education level and the monthly income. Gender, peer influence, land size, location of household and membership of environmental organization explain household waste utilization and separation behavior (Ekere, 2009). It has been reported that collection, transfer and transport practices are affected by improper bin collection systems, poor route planning, lack of information about collection schedule (Hazra and Goel, 2009), insufficient infrastructure (Moghadam et al., 2009), poor roads and number of vehicles for waste collection (Henry, 2006). Tadesse et al. (2008) analyzed the factors that influence household waste disposal decision making. Results showed that the supply of waste facilities significantly affects waste disposal choice. Inadequate supply of waste containers and longer distance to these containers increase the probability of waste dumping in open areas and roadsides relative to the use of communal containers. Insufficient financial resources limiting the safe disposal of waste in well equipped and engineered landfills and absence of legislation are mentioned by (Pokhrel and Viraraghavan, 2005).

During the last few decades, the problems associated with municipal solid waste (MSW) management have acquired an alarming dimension in Bangladesh. High population growth rate and increase of economic activities in the urban areas of developing countries combined with the lack of training in modern solid waste management practices complicate the efforts to improve the solid waste management services (Ahsan et al., 2014). In Bangladesh, the solid waste management has so far been ignored and is one of the least studied environmental issues. Recently the concerned stakeholders have begun to consider this sector to be an essential component to protect human health and nature. The urban population in Bangladesh has increased at a very steep rate of about $6 \%$ per year and concentrated mostly in six major cities, namely, Dhaka, Chittagong, Khulna, Rajshahi, Barisal, and Sylhet. Current estimations showed that about $13 \%$ of total population and 55 to $60 \%$ of total urban population are living in these cities (Alamgir, 2005).

Khulna, the third largest metropolitan city of Bangladesh, is in the southern part of the country with its location on the axis of Jessore-Mongla port, the second largest seaport of the country. The study area Khulna City Corporation area 45.65 square $\mathrm{km}$, located in between $24^{\circ} 45^{\prime}$ and $24^{\circ} 54^{\prime}$ north latitudes and in between $89^{\circ} 28^{\prime}$ and $89^{\circ} 35^{\prime}$ east longitudes. Khulna City Corporation area (KCC) has a population of about 1.4 million with 31 Wards. It's elevation is 7 feet above the MSL. Acording to Khulna City Corporation (KCC), Annual Report of Khulna, 2016, Khulna city generates approximately 520 ton/day of solid waste but waste carried by KCC to the final disposal is about 300 ton/day. So about 220 ton wastes are dumped illegally per day in Khulna city here and there. The current location of landfill is about 7-8 km away from the KCC area. (Rafizul, Alamgir, Howlader, Kraft and Haedrich, 2009), reported that the city authority generally manages the MSW however; recently, some NGOs, CBOs and private organization are working for door-to-door collection with city authority's initiatives. Door-to-door collection systems were introduced recently for MSW collection from generation sources, mainly from households, and major portion of wastes are disposed to the nearest secondary disposal site (Alamgir, Ahsan, McDonald, Upreti and Rafizul, 2005). (Haque, 2005), reported that the location of disposal (secondary) sites of KCC represents the unconsciousness about the environmental and public health hazards which arises from disposing of waste in improper location. A suitable site must have environmental safety criteria's. Criteria for site selection includes natural physical characteristics as well as socioeconomic, ecological, and land use factors (Debasish Adhikary and Shahidul Islam, 2015). (Riyad, Zohur-Uz-Zaman and Farid Hossain, 2015), has also described the present scenario of inconvenient bin placements in Khulna city. It is reported that KCC is responsible for collecting and removing the deposited solid waste in dustbins/containers surrounded by the whole city area and finally transporting it at the ultimate disposal sites. Residents are responsible for bringing their generated solid waste to KCC's primary collection points where dustbins/containers are situated. (Islam Rafizul, Risvi Kizer and Ashiqur Rahman, 2013), have proposed a GIS based optimized route plan for collection and disposal of municipal solid waste (MSW) from SDS to ultimate disposal site (UDS) in Khulna city. Many suggestions were considered in this spatial planning proposal while working in GIS, they are (i) identification of exact location of MSW bins with GPS demarcating on the base map; (ii) maintaining a record of SDSs; (iii) a map 
showing the road network in different areas; (iv) a map showing the distances between the bins; (v) location of the SDSs; (vi) record of available vehicles and equipment for MSW management; (vii) allocating a unique number to all the SDSs so it can be easily and quickly located in case of any complaint registered or planning and maintenance; (viii) maintaining a record about the type of SDSs and (ix) record of the responsibilities and assignment of work, equipments, vehicles etc. of the MSW maintenance and also the logistics information about the the transportation involved in the system. Figure 1 shows the map of Khulna City Corporation area.

GIS is a computer support tool used for capturing, storing, querying, analyzing and displaying spatial data from real world for a particular set of purposes. This technique is used to locate and analyse the existing waste collecting bins and containers and to generate optimal route for collecting solid wastes. GIS is a tool that not only reduces time and cost of site selection, but also provides a digital data bank for future monitoring program of site. (Shohel, et al., 2013), also showcased application of GIS in solid waste management for Khulna city. In his study, the criteria for suitable waste bin location includes natural physical characteristics and mental characteristics for user as well as socioeconomic, ecological, land use factors, user travel time, concern about public institute, easily access and publicly concern about environment road width.

\subsection{Solid waste management in KCC}

$\mathrm{KCC}$ is the formal public sector organization of the government that is responsible for SWM in KCC area. The SWMS by the KCC is shown in Figure 2.

\section{Map of the Khulna city corporation area}

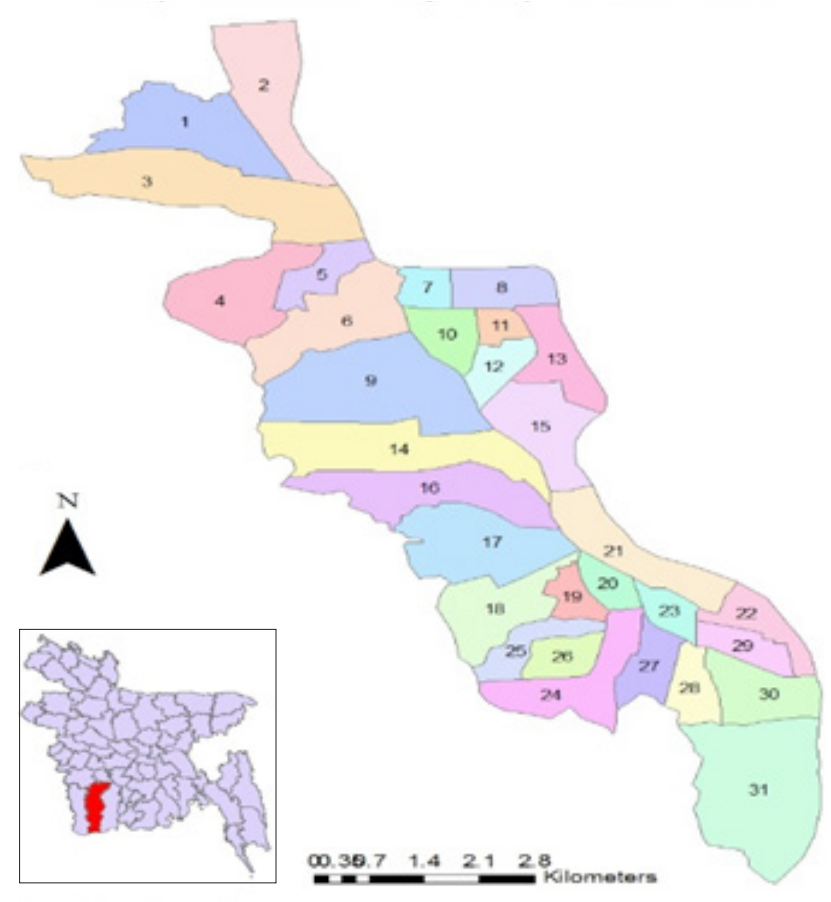

FIGURE 1: Khulna City Corporation.

\section{METHODOLOGY}

\subsection{Investigation of primary and secondary disposal site}

The questions of field survey for gathering the required information about the existing situation of primary point and SDS located in KCC and answers from city dwellers and other stakeholders were recorded. A straight espial and audit have been prosecuted among the native people and related organizations with a questionnaire survey. Study on the local people about their perception and feedback to SWM system organized by KCC and the way other people respond to it, is observed also for perceiving the management behaviour of solid waste. The detailed map had the information about road network, major building, religious buildings, cinema halls, land mark, and water streams. Information about waste bins location as well as open dumps were collected by general survey and entered in the GIS database.

\subsection{Model analysis}

Model is developed on GIS for selecting suitable location of waste bin in study area. Developing model has been used some considerations, there are:

Firstly, all contexts are included to the study area like as population, density, household waste generation, socio-economic condition and existing solid waste management consideration of study area.

Secondly, equal waste bin size and capacity like as concrete bin capacity is $1000 \mathrm{Kg}$ and haul container capacity is $2500 \mathrm{Kg}$.

Thirdly, per capita waste generation rate at $0.5 \mathrm{~kg} / \mathrm{day}$ are considered.

Fourthly, inhabitants are open choice to disposal waste service household to waste bin.

Methodology followed is shown in the Figure 3.

\section{RESULTS AND DISCUSSION}

\subsection{Current Situation of SWM from Questionnaire Survey}

The recent survey shows that about 500 tonnes wastes are produced daily in Khulna city where of the total, only 250 to 270 tons are collected and dumped into the open dumping ground at Rajbando landfills of Batiaghata upazila. The rest does not even reach to the dumping ground owing lack of logistic support and manpower. The remaining about 180 tons of uncollected wastes being dumped into drains, open spaces, road-sides and water-bodies, not only block the city's drainage links but also create an unhealthy and stinking environment. In absence of dustbins, residents of Khulna city force to dump wastes into drains, canals and road-sides. In the Khulna city, the main producers of solid waste are residences, whole and retail sale market places including shopping places, streets, hotels and restaurants, hospitals and private clinics, educational institutions, cinemas, bus, railway and launch/steamer ghats, slaughter houses etc. In the collection system, normally NGOs and CBOs conduct the door to door collection. Now a day's city corporation authority also conducts door to door collection system in a small area. 


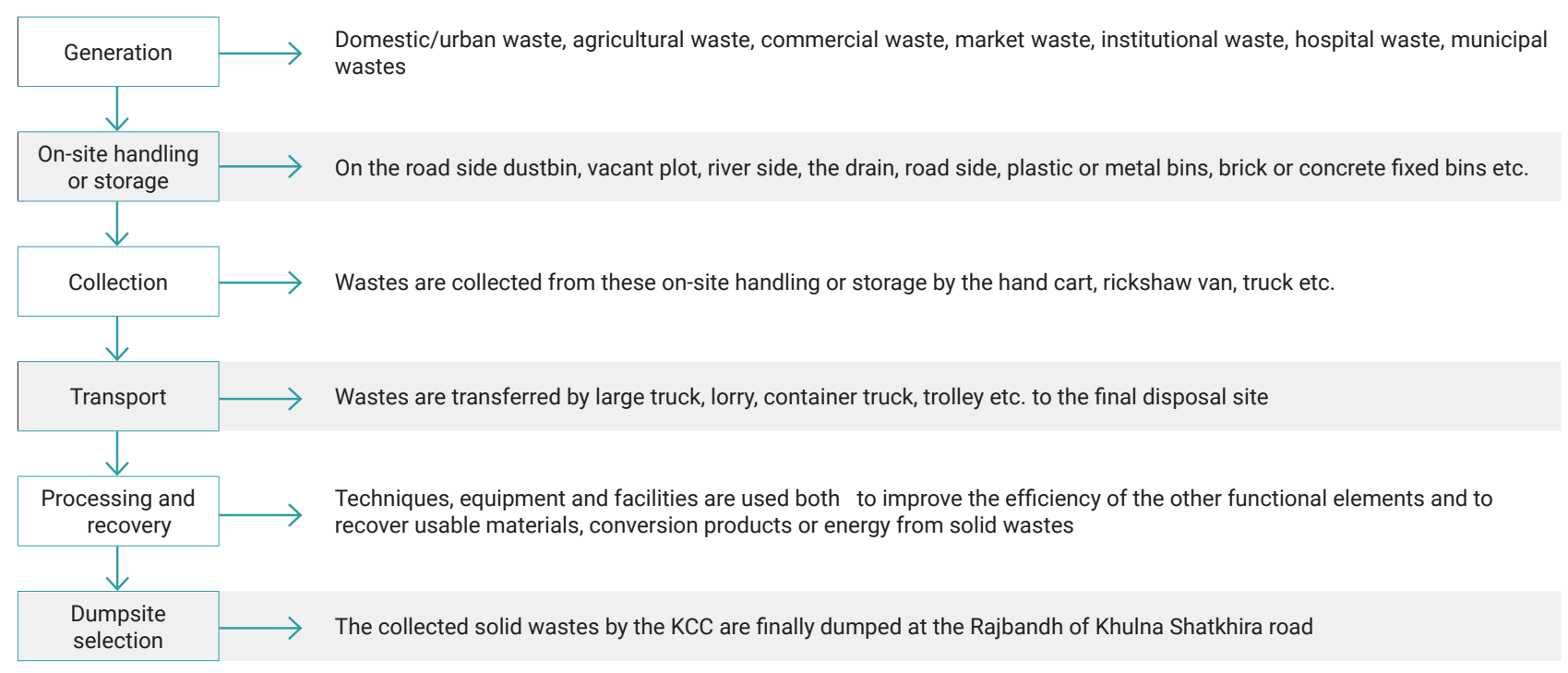

FIGURE 2: Solid waste management system in KCC.



FIGURE 3: Flow chart of methodology.

To investigate the present scenario of MSW management in Khulna city, questionnaire survey among 200 responsible people has been conducted. It was noticed that, KCC collects around 55\%, non-government organization and community based organization (NGO and $\mathrm{CBO}$ ) collects $10 \%$ of MSW from the household and the unmanaged waste remains $35 \%$ here and there into drains, canals and road-sides of Khulna city (Figure 4).

$\mathrm{KCC}$ is responsible for collection and removal of deposited solid waste in dustbins/containers surrounded the whole city area and finally transport it at the ultimate disposal sites. Residents are responsible for bringing their generated solid waste to KCC's primary collection points where dustbins/containers are situated. Recently, NGO's have introduced door-to-door collection of solid waste in different area of Khulna City Corporation for the management of solid waste in cooperation with the city authority and respective ward Commissioner. From the questionnaire survey, it is reported that door-to-door col- lection system is most preferable waste collection system as household themselves especially women do not have any permanent disposal of waste near their location. People are sometimes unconscious to throw the waste to the streets rather than using dustbin. For better review, a bar diagram (Figure 5) is provided here.

An analysis of the household participation is shown in Figure 6 . On the average $70 \%$ of the households in the study area are participating in the collection system. Out of the remaining non-participating $30 \%$, the majority, i.e., $21 \%$ lives in areas that are of rural characteristics. The households of this rural criteria discard their waste in an open excavation within their own premises. The actual non-participation is $9 \%$ of which $6 \%$ are still not motivated, another $3 \%$ do not pay. The survey was also carried out about the collection prototype of MSW from SDS among 200 responsible persons and stakeholders, it was noticed that KCC collects MSW from SDS 168 (84\%) once per day, 28 (14\%) twice per day and 4 (2\%) more and shown in Figure 7. 


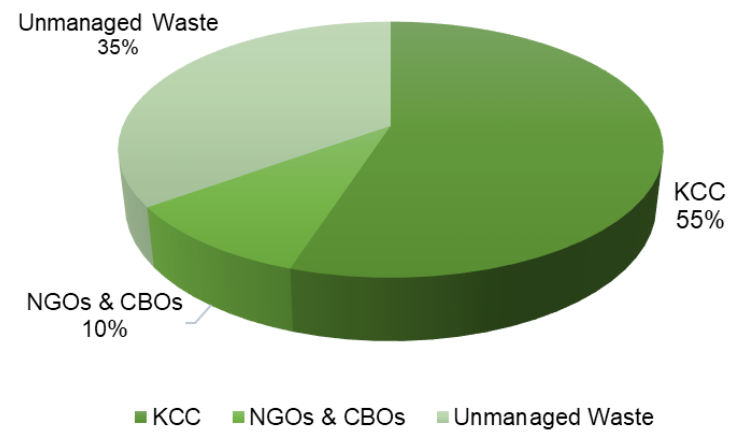

FIGURE 4: Waste management capacity.

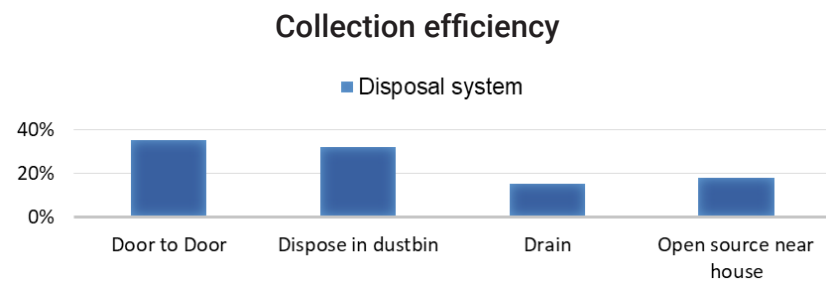

FIGURE 5: Distribution of waste disposal.
Figure 8 shows source storage aspects of MSW as revealed from people comments. The survey results reveal that (Figure $8 \mathrm{a}$ ) that $62 \%$ do the source storage of the generated wastes in a dustbin, $18 \%$ polythene bag, $15 \%$ in open space. Most of the people practice mixed storage at source (Figure 8b). People are not happy (Figure 9) with present performance of city authority to manage the MSW problems. Figure 10 shows that most of the people prefer daytime, 10:00am to 2:00pm for the disposal of wastes from source, while a considerable portion (18\%) do not have any choice of fixed time. It is clear that the present SWM in Khulna city is not well sufficient and should be improved immediately. So, an initiative for integrated urban SWM is essential to minimize waste generation with supporting reuse and recycling options in Khulna city.

\subsection{Analysis of service coverage of existing waste bin and container}

At present, there are approximately 180 waste bins and 35 secondary disposal sites (SDS) located in KCC area. This study is based on collected field data, questionnaire survey and literature review to identify the present status of solid waste management in Khulna City Corporation. From field survey of the study area, it was found that the preferable distance of primary waste bin for the households ranges approximately $500 \mathrm{~m}$, which is not covering the full area. The capacity of each waste bins ranges between 500 $\mathrm{kg}$ to $1000 \mathrm{~kg}$ and from estimating the study area, per capita waste generation rate is $0.5 \mathrm{~kg}$ per day. Among 35 SDS points, there are 14 open and 21 haul containers. Model is developed on GIS for identification and selection of waste bin in the study area. GIS as a tool which is used in the analysis of the existing situation of waste bin management and then the selection of some suitable locations and also in the requirement of number of the waste bins. The existing waste bins are located in GIS model by pointing the exact location of waste bins in geo-image of Khulna City Corporation by Google map. This situation assisted to improve the service efficiency. Determinations of required number of waste containers were done based on the population of each ward and the capacity of each container. The optimum location of waste bins and containers had been suggested with present containers and bins. Self-judgment was applied to choose the essential locations. KCC solid waste management facility is not enough to cover the study area fully on time. There are 21 different size KCC containers in the study area retaining about 65 tonnes capacity. There are 14 open SDS in Khulna city in where people and KCC workers dispose their waste and it's capacity is 28 tonnes. The KCC workers collect wastes at day-time from residential areas but the KCC trucks collected the wastes at night or at early in the morning. While city authority has some limited numbers of non-motorized Rickshaw vans and Hand trolley, those are mainly used for the collection of MSW from Community bins located at roadside, home side, near market, and transfer to SDS. Besides this drain sludge's are also collected by these vans. The existing waste bin and containers can hold about $54.6 \%$ generated waste of the study area. Rests of the waste (45.4\%) are dumped illegally here and there. Table 1 shows the total waste collection from the waste bins and containers in Khulna city.

Following, Figure 11 shows location of primary points
A Status of Household Participation

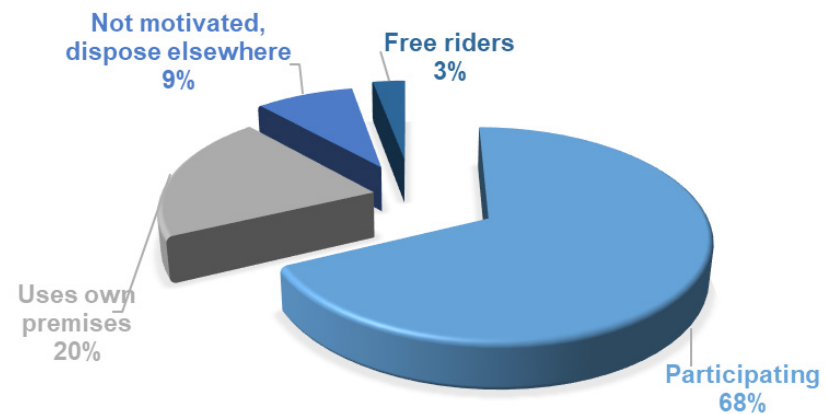

FIGURE 6: Status of household participation.
KCC Collects Waste From SDS

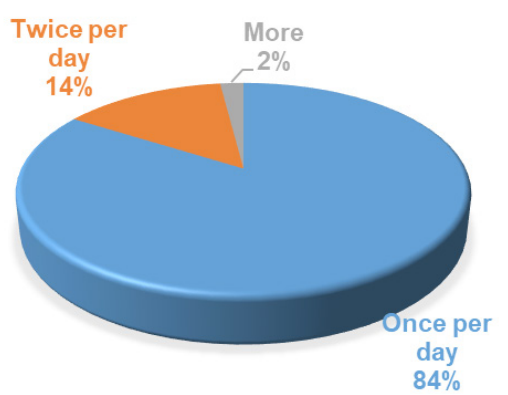

FIGURE 7: Prototype for MSW from SDS. 


\section{Store of household waste}

Dustbin $\mathbf{m}$ Paper Bag $\mathbf{m}$ Open Space $\mathbf{m}$ Do not Store

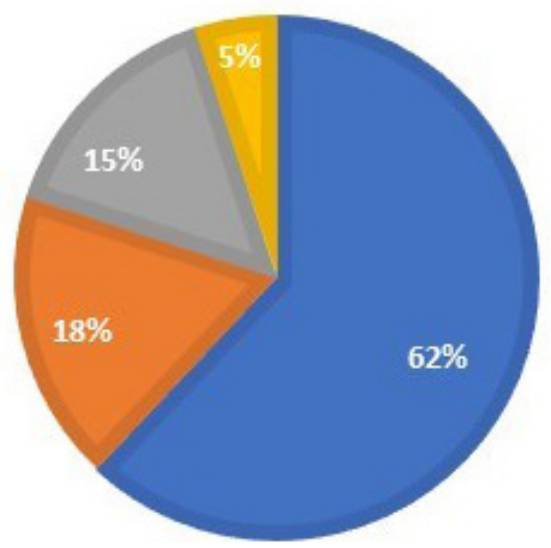

(a)
Type of waste stored in dustbin

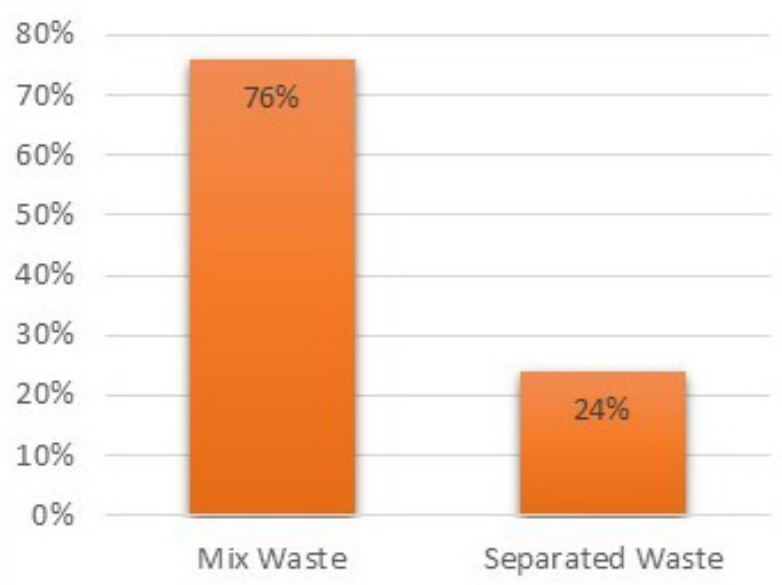

(b)

FIGURE 8: Source storage aspects of MSW as revealed from people comments.

\section{Present situation of MSW management}

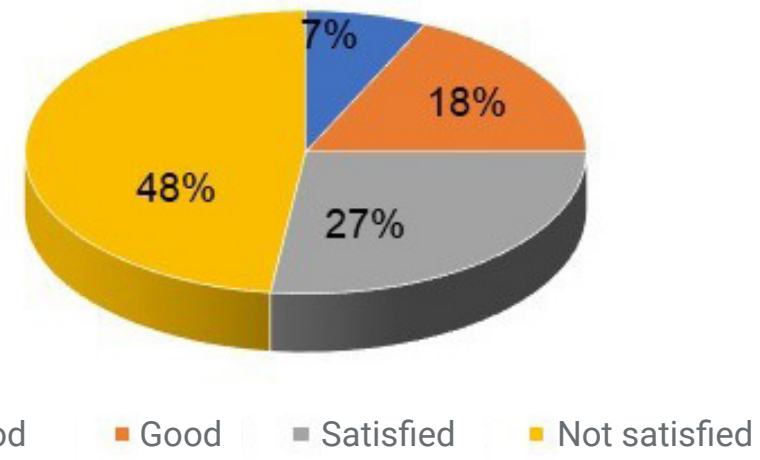

FIGURE 9: Opinions on the performance of city authority about MSW management.

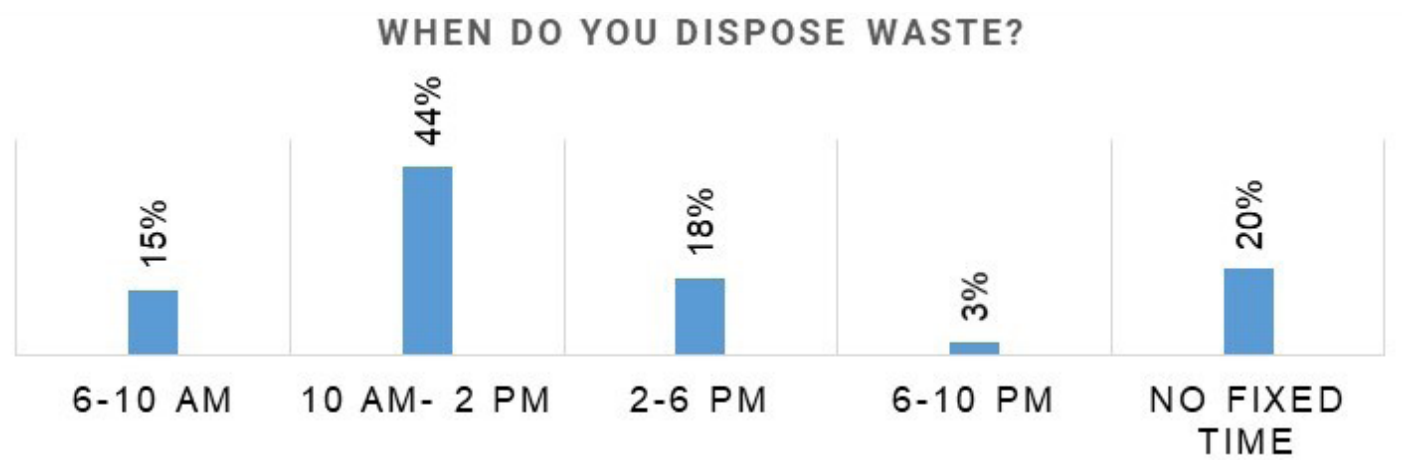

FIGURE 10: Disposal of waste

in KCC. At present, there are 180 bins in KCC. Figure 12 shows the service area of each dustbin. Here the area of influence or service area of a single dustbin considers 500 meter radius (highest) form its center. The capacity of each waste bins ranges between $500 \mathrm{~kg}$ to $100 \mathrm{~kg}$ and generation rate is considered $0.5 \mathrm{~kg}$ per capita per day. People in ward no. $7,10,11,12,19,20,25,26$ have the full services with the existing dustbins. At ward-3 and ward-31, there are no such bins or containers for solid waste disposal. Population density of that site in KCC area is lower than the other parts in KCC area. Community based SW collection vans collect wastes once or twice in a week from that site. Ward no. 7, 10, 11, 12, 19, 20, 25, 26 of the study area are fully residential area and waste collection practice is per- 
TABLE 1: Capacity of existing waste bins and containers in Khulna city.

\begin{tabular}{|c|c|c|c|}
\hline Types & Capacity (tonnes) & Total Number & Total Waste Collection (tonnes) \\
\hline \multirow{2}{*}{ KCC containers } & 2.5 & 16 & 40 \\
\hline & 5.0 & 5 & 25 \\
\hline Open SDS & 2.0 & 14 & 28 \\
\hline \multirow[t]{2}{*}{ Waste Bins (brick and concrete) } & 1 & 180 & 180 \\
\hline & & & Total = 273 tonne $(54.60 \%)$ \\
\hline
\end{tabular}

formed regularly by KCC authority. With some exceptions of illegal dumping, ward 2, 4, 14, 16, 22 and 23 have quite good waste management practices. In some part of the ward-1 and ward-9, mainly in slum areas, unprivileged peoples had a lack of proper sanitation and solid waste dumping facilities and only wastes are collected at night from the adjacent containers. So, these sites need proper SWM observation.

Table 2 shows service category dustbin in KCC, which has three category: only served area, over served are and un-served area. Only served area means the area which is properly served by one KCC containers. Overserved area means more than 2 dustbin facility. And the area which is not served by any dustbin facilities is known as unserved area. As for example, ward no 01 has three category but ward no 10 has two category- only served area and over served area. Table 3 and Table 4 shows the estimation only served, over served and un-served area and population. Figure 13 shows distribution of overserved dustbin service in KCC. Figure 14 represents the SDS location and service area in KCC. Though KCC managed solid wastes on ward basis, it is quite impossible to reach $100 \%$ efficiency in Municipal Solid Waste Management (MSWM). But adequate SWM can improve the SWM efficiency to a substantial extent. Distribution of waste disposal, prototype collection for MSW from SDS, household participation, initiated by local community and supported by KCC was observed. But in some areas under KCC, it is noticed that the SWM practice was not sustained thoroughly which results medley waste disposal and causes environmental pollution.

From the questionnaire survey, it is found that solid wastes are generated more from March to August month of the year. In rainy season, the scenario was quite worse with the flooding the wastes to the roads with rain water and block the seepage part and drainage systems for flowing the dirty water. Comparatively KCC waste collection authority helps to minimize the SW problem, but the management of waste collection from household by the local SW collecting bodies are responsible for the illegal waste disposal. As the residential area was highly over-populat-

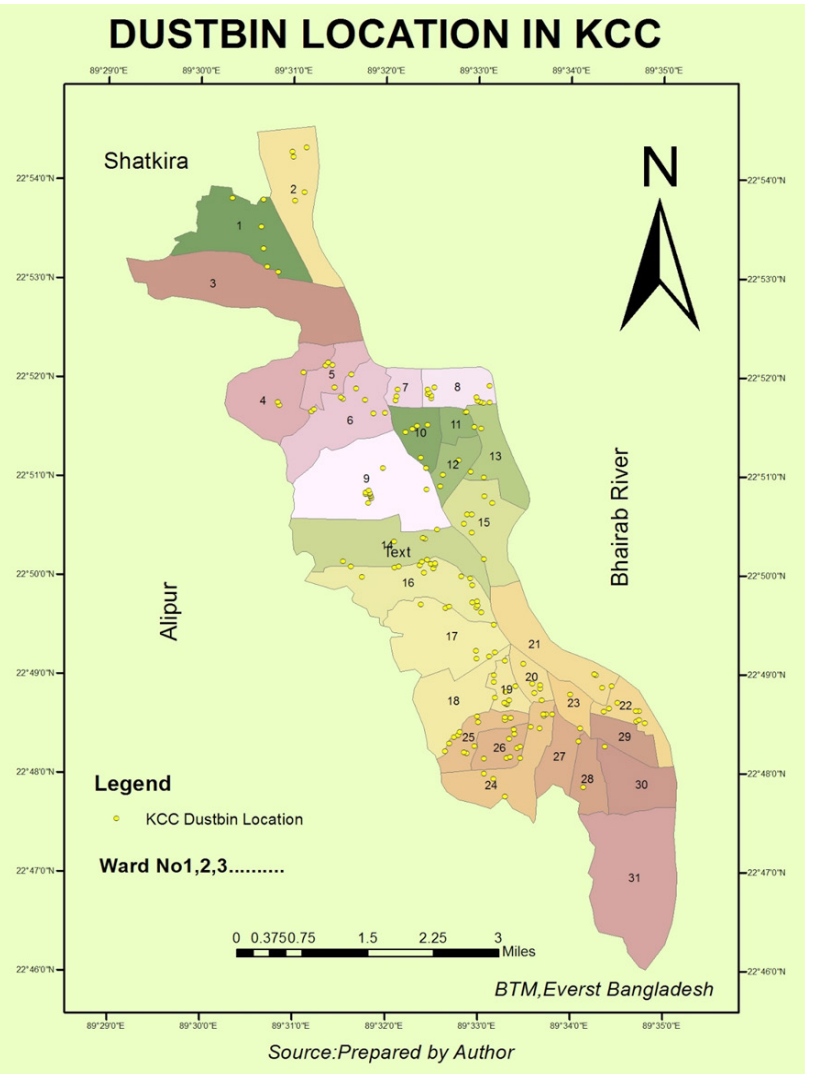

FIGURE 11: Location of primary points in KCC.

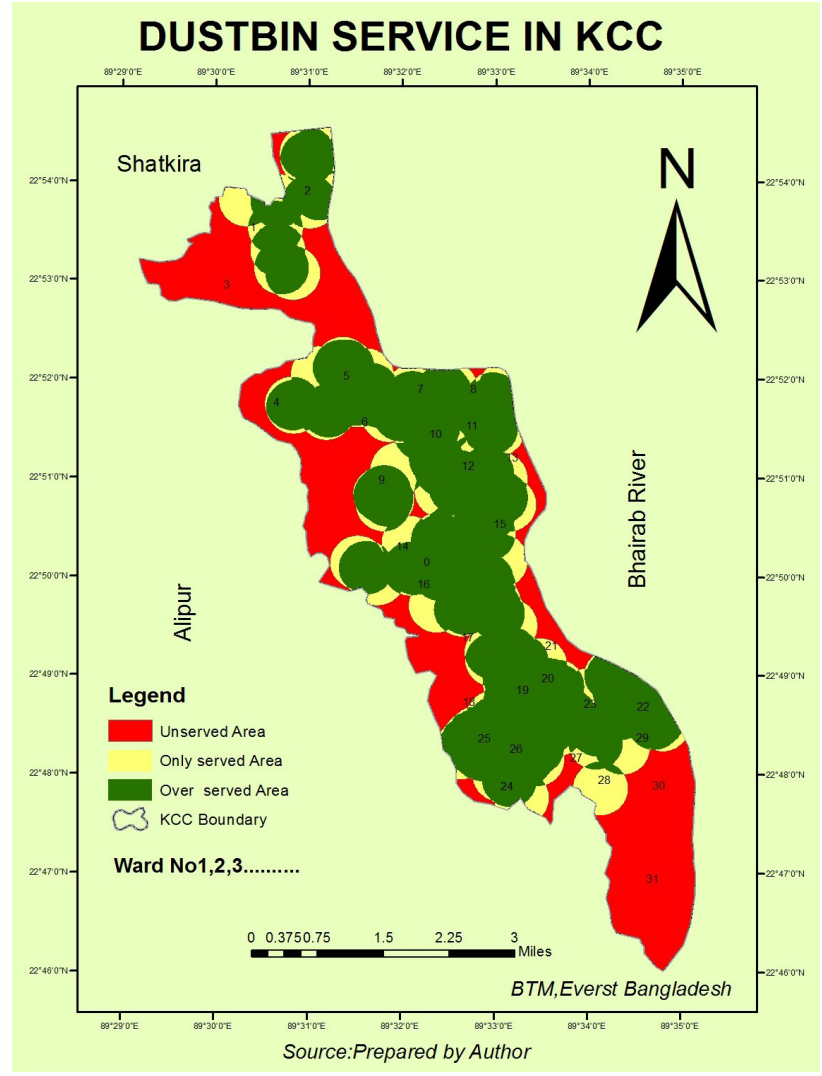

FIGURE 12: Dustbin Service in KCC. 
TABLE 2: Service category dustbin in KCC.

\begin{tabular}{|c|c|c|c|c|}
\hline Ward No & Only served Area (No) & Over Served area (No) & Unserved Area(no) & Grand Total \\
\hline 1 & 1 & 1 & 1 & 3 \\
\hline 10 & 1 & 1 & & 2 \\
\hline 11 & 1 & 1 & & 2 \\
\hline 12 & 1 & 1 & & 2 \\
\hline 13 & 1 & 1 & 1 & 3 \\
\hline 14 & 1 & 1 & 1 & 3 \\
\hline 15 & 1 & 1 & 1 & 3 \\
\hline 16 & 1 & 1 & 1 & 3 \\
\hline 17 & 1 & 1 & 1 & 3 \\
\hline 18 & 1 & 1 & 1 & 3 \\
\hline 19 & & 1 & & 1 \\
\hline 2 & 1 & 1 & 1 & 3 \\
\hline 20 & & 1 & & 1 \\
\hline 21 & 1 & 1 & 1 & 3 \\
\hline 22 & 1 & 1 & 1 & 3 \\
\hline 23 & 1 & 1 & & 2 \\
\hline 24 & 1 & 1 & 1 & 3 \\
\hline 25 & 1 & 1 & & 2 \\
\hline 26 & & 1 & & 1 \\
\hline 27 & 1 & 1 & 1 & 3 \\
\hline 28 & 1 & 1 & 1 & 3 \\
\hline 29 & 1 & 1 & 1 & 3 \\
\hline 3 & 1 & 1 & 1 & 3 \\
\hline 30 & 1 & 1 & 1 & 3 \\
\hline 31 & 1 & & 1 & 2 \\
\hline 4 & 1 & 1 & 1 & 3 \\
\hline 5 & 1 & 1 & 1 & 3 \\
\hline 6 & 1 & 1 & 1 & 3 \\
\hline 7 & 1 & 1 & & 2 \\
\hline 8 & 1 & 1 & 1 & 3 \\
\hline 9 & 1 & 1 & 1 & 3 \\
\hline Grand Total & 28 & 30 & 22 & 80 \\
\hline
\end{tabular}

TABLE 3: Served, over server and unserved area (Sq. km).

\begin{tabular}{|c|c|c|c|c|}
\hline Ward No & Only served Area & Over Served area & Unserved Area & Grand Total \\
\hline 1 & 2.227856 & 2.227856 & 2.227856 & 6.683568 \\
\hline 10 & 0.809781 & 0.809781 & & 1.619562 \\
\hline 11 & 0.364905 & 0.364905 & & 0.72981 \\
\hline 12 & 0.659046 & 0.659046 & & 1.318092 \\
\hline 13 & 1.119565 & 1.119565 & 1.119565 & 3.358695 \\
\hline 14 & 2.691663 & 2.691663 & 2.691663 & 8.074989 \\
\hline 15 & 1.659229 & 1.659229 & 1.659229 & 4.977687 \\
\hline 16 & 2.253474 & 2.253474 & 2.253474 & 6.760422 \\
\hline 17 & 2.298736 & 2.298736 & 2.298736 & 6.896208 \\
\hline 18 & 1.617838 & 1.617838 & 1.617838 & 4.853514 \\
\hline 19 & & 0.492191 & & 0.492191 \\
\hline 2 & 2.179358 & 2.179358 & 2.179358 & 6.538074 \\
\hline 20 & & 0.499665 & & 0.499665 \\
\hline 21 & 1.725098 & 1.725098 & 1.725098 & 5.175294 \\
\hline 22 & 0.825691 & 0.825691 & 0.825691 & 2.477073 \\
\hline
\end{tabular}




\begin{tabular}{|c|c|c|c|c|}
\hline Ward No & Only served Area & Over Served area & Unserved Area & Grand Total \\
\hline 23 & 0.510105 & 0.510105 & & 1.02021 \\
\hline 24 & 1.678222 & 1.678222 & 1.678222 & 5.034666 \\
\hline 25 & 0.762184 & 0.762184 & & 1.524368 \\
\hline 26 & & 0.66492 & & 0.66492 \\
\hline 27 & 0.811904 & 0.811904 & 0.811904 & 2.435712 \\
\hline 28 & 0.735918 & 0.735918 & 0.735918 & 2.207754 \\
\hline 29 & 0.659339 & 0.659339 & 0.659339 & 1.978017 \\
\hline 3 & 3.657733 & 3.657733 & 3.657733 & 10.973199 \\
\hline 30 & 1.320933 & 1.320933 & 1.320933 & 3.962799 \\
\hline 31 & 3.902639 & & 3.902639 & 7.805278 \\
\hline 4 & 2.034172 & 2.034172 & 2.034172 & 6.102516 \\
\hline 5 & 0.775361 & 0.775361 & 0.775361 & 2.326083 \\
\hline 6 & 2.159462 & 2.159462 & 2.159462 & 6.478386 \\
\hline 7 & 0.471743 & 0.471743 & & 0.943486 \\
\hline 8 & 0.943937 & 0.943937 & 0.943937 & 2.831811 \\
\hline 9 & 3.540127 & 3.540127 & 3.540127 & 10.620381 \\
\hline Grand Total & 44.396019 & 42.150156 & 40.818255 & 127.36443 \\
\hline
\end{tabular}

TABLE 4: Served, over served and unserved population (as 2020, BBS).

\begin{tabular}{|c|c|c|c|c|}
\hline Ward No & Only served Pop. & Over Served Pop. & Unserved Pop & Grand Total \\
\hline 1 & 31370 & 31370 & 31370 & 94110 \\
\hline 10 & 28600 & 28600 & & 57200 \\
\hline 11 & 29960 & 29960 & & 59920 \\
\hline 12 & 80370 & 80370 & & 160740 \\
\hline 13 & 30830 & 30830 & 30830 & 92490 \\
\hline 14 & 40840 & 40840 & 40840 & 122520 \\
\hline 15 & 39730 & 39730 & 39730 & 119190 \\
\hline 16 & 55420 & 55420 & 55420 & 166260 \\
\hline 17 & 46880 & 46880 & 46880 & 140640 \\
\hline 18 & 25890 & 25890 & 25890 & 77670 \\
\hline 19 & & 40650 & & 40650 \\
\hline 2 & 29060 & 29060 & 29060 & 87180 \\
\hline 20 & & 34810 & & 34810 \\
\hline 21 & 38590 & 38590 & 38590 & 115770 \\
\hline 22 & 33410 & 33410 & 33410 & 100230 \\
\hline 23 & 28310 & 28310 & & 56620 \\
\hline 24 & 66350 & 66350 & 66350 & 199050 \\
\hline 25 & 41860 & 41860 & & 83720 \\
\hline 26 & & 27930 & & 27930 \\
\hline 27 & 48630 & 48630 & 48630 & 145890 \\
\hline 28 & 34600 & 34600 & 34600 & 103800 \\
\hline 29 & 31550 & 31550 & 31550 & 94650 \\
\hline 3 & 35550 & 35550 & 35550 & 106650 \\
\hline 30 & 55330 & 55330 & 55330 & 165990 \\
\hline 31 & 50350 & & 50350 & 100700 \\
\hline 4 & 22080 & 22080 & 22080 & 66240 \\
\hline 5 & 23650 & 23650 & 23650 & 70950 \\
\hline 6 & 32430 & 32430 & 32430 & 97290 \\
\hline 7 & 22870 & 22870 & & 45740 \\
\hline 8 & 28640 & 28640 & 28640 & 85920 \\
\hline 9 & 53460 & 53460 & 53460 & 160380 \\
\hline Grand Total & 1086610 & 1139650 & 854640 & 3080900 \\
\hline
\end{tabular}


DISTRIBUTION OF OVERSERVE DUSTBIN SERVICE IN KCC

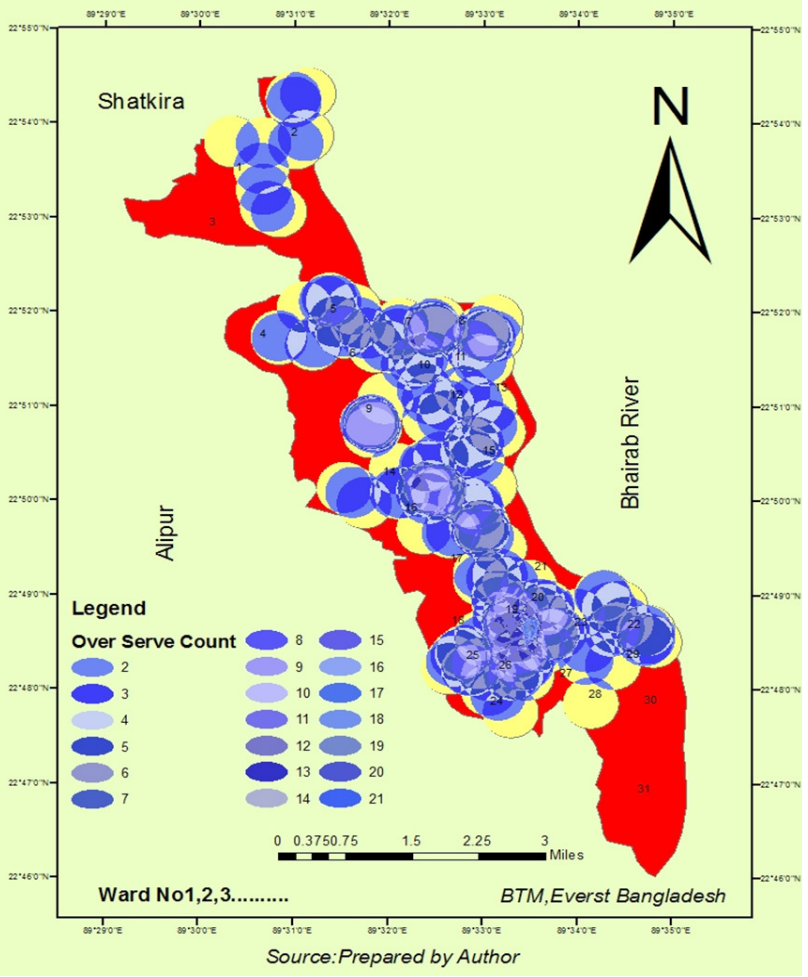

FIGURE 13: Distribution of overserved dustbin service in KCC.

ed, unconcerned people threw their wastes beside the playground, along the roadside and to the open-spaces as well which induce odor and health problems. Waste accumulation around the waste containers reflected traffic problem. The pedestrians can also get affected by odor problem induced by SW around the containers beside the roads.

\section{CONCLUSIONS}

After the analysis of the present situation of KCC area, it is found that about $55 \%$ of generated SW had been collected by KCC with the existing bins and containers. So, problem arises when $45 \%$ waste are illegally dumping which can cause various environmental problems and diseases. The location of dustbin and container is identified in the map by using GIS for better review. By analyzing the capacity of bins, the total served area is found $86.57 \mathrm{sq} . \mathrm{km}$ and total unserved area is about $40.82 \mathrm{sq}$. km. Also people's participation and concern are the most dominant supports to clean the surroundings.

\section{AKNOWLEDGEMENTS}

The authors acquired great deal of knowledge about GIS from Md. Esrazul Zannat sir, Urban and Regional Planning, Khulna University of Engineering and Technology. He possesses a good experience of various GIS projects.

The authors are obliged to the people of the study area who helped supplying all necessary information and active co-operative through questionnaire in this regard.

Finally, the authors are expressing deep gratitude to
SDS LOCATION \& SERVICE AREA IN KCC

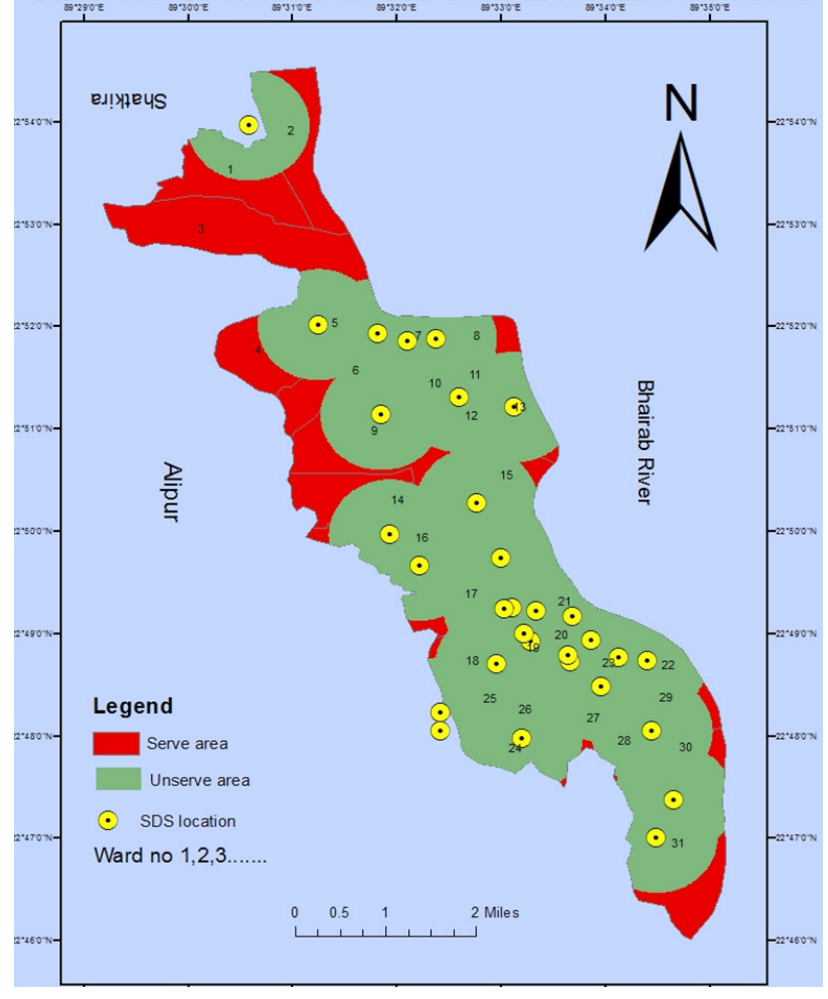

FIGURE 14: SDS location and service area in KCC.

parents and family for funding and inspiration in all stages of hard working.

\section{REFERENCES}

(BBS), B.B. (2014). Statistical Year Book of Bangladesh. Dhaka: Bangladesh.

A. Ahsan, M. Alamgir, M. M. El-Sergany, S. Shams, M. K. Rowshon, and N. N. Nik Daud (2014). Assessment of Municipal Solid Waste Management System in a Developing Country. Chinese Journal of Engineering, Article ID 561935, 11 pages.

A.S.M. Riyad, Zohur-Uz-Zaman, and Sk. Farid Hossain (2015). Sustainable Management Scheme for Household and Academic Institutional Solid Waste generation: A Case Study in Khulna Metropolitan City. International Journal of Renewable Energy and Environmental Engineering.

Alamgir M, Ahsan A, McDonald CP, Upreti BN, and Rafizul IM. (2005) Present Status of MSWM in Bangladesh, Waste-The Social Context,. International Journal of Engineering Research-Online.

Benitez S.O., L.-O.G. (2008). Mathematical Modeling to Predict Residential Solid Waste Generation. ITN-BUET, Department of Environment (DoE). Dhaka, Bangladesh: Waste Management.

Debasish Adhikary, and Md. Shahidul Islam. (2015). Feasibility Analysis of Eco-Friendly Municipal Waste Management in Khulna City. International Conference on Mechanical, Industrial and Materials Engineering 2015 (ICMIME2015). RUET, Rajshahi, Bangladesh.

Ekere, W.M. (2009). Factors influencing waste separation and utilization among households in the Lake Victoria Crescent, Uganda. Journal of Waste Management 29, 3047-3051.

Gazi Moniruzzaman. (2015, July 27). Uncollected Wastes Make Khulna City Unhealthy.

Haque, M. (2005). "Site Suitability Analysis for Solid Waste Disposal Using GIS: A Case Study on KCC area,". Khulna.

Hazra T., and Goel, S. (2009). Solid Waste Management in Kolkata, India. Practices and Challenges Waste Management 29, 470-478.

Henry, R. Y. (2006.). Municipal solid waste management challenges in developing countries - Kenyan case study. Journal of Waste Management 26, 92-100 
Islam M. Rafizul, M. Risvi Kizer, and M. Ashiqur Rahman. (2013). Secondary disposal sites for solid waste management in khulna city and optimizing routes for final disposal using gis. International Journal of Engineering Research-Online.

James, A. (1997). Riegel's Handbook of Industrial Chemistry. India: CBS Publishers and Distributors.

Kathiravale S, and Muhd Yunus MN . (2008). Waste to Wealth. Asia Europe Journal 6(2): 359-371.

KCC (Khulna City Corporation). (2016). Annual Report of Khulna. KCC Bhaban, Khulna, Bangladesh.

M. Alamgir, C. M. (2005). Integrated Management and Safe Disposal of Municipal Solid Waste in Least Developed Asian Countries:. A Feasibility Study, WasteSafe Publication, Khulna, Bangladesh.

Moghadam, M. M. (2009). Municipal solid waste management in Rasht City. Iran Journal of Waste Management 29, 485-489.

Pokhrel, D., and Viraraghavan, T. (2005). Municipal solid waste management in Nepal: practices and challenges. Journal of Waste Management 25, 555-562.

Rafizul IM, Alamgir M, Howlader MK, Kraft E, and Haedrich G. (2009). Construction and Evaluation of Sanitary Landfill Lysimeter in Bangladesh. Waste Safe 2009. KUET, Khulna.
Ramachandra, T., and Saira, V. (2003). Exploring Possibilities of Achieving Sustainability in Solis Waste Management. Indian JI Environmental Health, 45 (4):255-264.

Shohel, M., Rafizul, I., Roy, S., Asma, U., Hasibul, M., and Didarul, M. (2013). GIS application for suitable location of waste bin for solid waste management in Khulna city. Khulna University of Engineering and Technology (KUET), Department of Civil Engineering, Khulna-9203, BANGLADESH: International Journal of Engineering Research-Online.

Sujauddin, M., Huda, M.S, and Rafiqul Hoque, A.T.M. (2008). Household solid waste charecteristics and management in Chittagong, Bangladesh. Journal of Waste Mangwement 28, 1688-1695.

Tadesse, T. R. (2008). Household waste disposal in Mekelle city. Northern Ethiopia Journal of Waste Management 28, 2003-2012.

Visvanathan, C., and Trankler, J. (2004). Municipal Solid Waste Management in Asia. Asian Institute of Technology. Asian Regional Research Program on Environmental Tescnology (ARRPET).

Wagner, T., and Arnold, P. . (2008). A new model for solid waste management: an analysis of the Nova Scotia MSW strategy. Journal of Cleaner Production 16(4), 410-421. 